\title{
ANÁLISE DOS EFEITOS DA INTERVENÇÃO GOVERNAMENTAL NA COMPETITIVIDADE DA PRODUÇÃO DE SOJA EM GRÃOS NO MATO GROSSO DO SUL
}

\author{
ANALYSIS OF THE EFFECTS OF GOVERNMENT INTERVENTION IN THE \\ COMPETITIVENESS OF SOYBEAN PRODUCTION IN GRAINS IN MATO GROSSO DO SUL
}

\section{Mayra Batista Bitencourt Fagundes}

Professora Doutora em Economia Aplicada pela Universidade Federal de Viçosa; Professora nos cursos de Pós-Graduação em Administração com ênfase em Gestão em Agronegócio e de Graduação em

Economia da Universidade Federal de Mato Grosso do Sul.

\section{Caroline Giusti de Araújo}

Graduanda em Ciências Econômicas da Universidade Federal de São Carlos.

\section{Valéria Silva Mortari}

Graduanda em Ciências Econômicas da Universidade Federal de São Carlos.

\section{Fábio Santos Rebelo}

Graduando em Ciências Econômicas da Universidade Federal de Mato Grosso do Sul.

\section{Patricia Rodrigues}

Graduanda em Ciências Econômicas da Universidade Federal de Mato Grosso do Sul.

\section{RESUMO}

Este artigo objetivou analisar a competitividade da cadeia produtiva de soja no Estado de Mato Grosso do Sul. Foi adotada a metodologia quantitativa desenvolvida por meio de um estudo exploratório, de forma que o método instrumental utilizado no estudo foi a Matriz de Análise de Política (MAP) a fim de mostrar o benefício da intervenção governamental no mercado agrícola. Os resultados gerados indicam que, embora o Estado de Mato Grosso do Sul seja competitivo, é possível ampliar o desenvolvimento regional mediante a atratividade de indústrias pertencentes à cadeia de soja, por meio de políticas públicas. Com isso, conclui-se que a melhoria da competitividade sul-mato-grossense seria estendida pela ampliação da intervenção estatal, principalmente no que se refere à equiparação do ICMS, expandindo, assim, os horizontes da economia do Estado.

Palavras-chave: Matriz de Análise de Política; políticas públicas; soja.

\section{ABSTRACT}

This article aims to analyze the competitiveness of the supply chain of soy in Mato Grosso do Sul was adopted a quantitative methodology developed through an exploratory study, so that the instrumental method used in the study was the Policy Analysis Matrix (PAM) in order to show the benefit of government intervention in the agricultural market. The generated results indicate that although the state of Mato Grosso do Sul is competitive can expand regional development through the attractiveness industries belonging to the chain of soybeans through public policies. Thus, we conclude that improving the competitiveness of South Mato Grosso would be extended by the expansion of state intervention, especially with regard to the assimilation of ICMS, thus expanding the horizons of the state economy.

Keywords: Policy Analysis Matrix; public policies; soy.

Endereços dos autores:

Mayra Batista Bitencourt Fagundes

bitencourtmayra@gmail.com

Caroline Giusti de Araújo

carolgiustiaraujo@gmail.com
Fábio Santos Rebelo

fabio_srebelo@hotmail.com
Patricia Rodrigues

patricia_rodrigues1992@hotmail.com 


\section{INTRODUÇÃO}

A soja consiste em uma das maiores culturas do setor agroindustrial no Brasil, atingindo na safra de 2010/2011 cerca de 24 milhões de hectares plantados. O país é o segundo maior produtor mundial de soja em grãos, com uma produção estimada em 75 milhões de toneladas e produtividade média de $3.106 \mathrm{~kg} / \mathrm{ha}$. A relevância econômica da soja no cenário internacional pode ser observada pela significativa exportação, de US\$17,1 bilhões em 2010 (EMBRAPA, 2011). Nota-se que a ascensão da produção da soja em grãos proporcionou a exploração de terras antes não cultivadas, o abastecimento do mercado interno, o aumento das exportações e, por fim, a geração de emprego e renda.

Caracterizada como uma das cinco grandes regiões brasileiras, o Centro-Oeste possui quatro unidades federativas: Mato Grosso (MT), Mato Grosso do Sul (MS), Goiás (GO) e Distrito Federal (DF). Em 2011, acompanhando a tendência nacional na produção de soja, o Centro-Oeste apresentou produção de 33.767.787 toneladas, sendo responsável por $45 \%$ da produção nacional, sucedido pelo Sul, Nordeste, Sudeste e Norte, respectivamente (SIDRA/IBGE, 2011).

Da mesma forma, o ano de 2012 apresentou maior dinamismo no setor agrícola, com projeções de crescimento do grão para 1.127.055 toneladas $(3,34 \%)$, apesar de o crescimento econômico, nesse ano, ter sido moderado para a região. Embora os indicadores mostrem que a área plantada de soja no país teve um aumento relativo de 2011 para 2012, sua produção não acompanhou este crescimento devido às condições climáticas desfavoráveis na safra de 2012. Sendo válido ressaltar que a safra 2012/2013 possivelmente terá sua produção ameaçada, pois a soja na bolsa de Chicago apresentou baixa nos preços em 2012, concomitante ao aumento do dólar, ou seja, o preço da safra tende a ser reduzido, tendo em vista que o Brasil é um tomador de preço no mercado internacional, portanto, é possível que a receita do produtor venha a ser reduzida, enquanto os custos de produção se encontrarão em ascensão, devido ao provável aumento do preço nos insumos.
O MS encontra-se como o sexto maior produtor de soja do país, produzindo um total de 5.079.581 toneladas em 2011 (SIDRA/IBGE, 2011). Em contrapartida, MT, o maior produtor de soja do país, teve sua produção contabilizada em 20.800.544 toneladas (SIDRA/ IBGE, 2011); um dos fatores que propicia esta grande produção deve-se ao fato de MT ter a maior área plantada em relação aos demais Estados (6.400.000 de hectares) (EMBRAPA, 2011). No quesito rendimento médio, a diferença apresentada entre os Estados é de $300 \mathrm{~kg} / \mathrm{ha}$, sendo MT com maior produtividade. Observa-se que, além de maior produtor nacional de soja, o MT, de janeiro a agosto de 2011, exibiu o mais alto valor em exportação, totalizando US\$ 3.694.301.361 e um volume de 7.506.421 toneladas (ANEC, 2011), posição esta que o Estado tende a ocupar nos próximos anos.

Segundo Coronel, Alves e Santos (2007), a introdução da soja em MS se deu no final dos anos 1960, trazida por arrendatários do sul do país, atraídos, principalmente, pela grande quantidade de terras ociosas a baixo preço. Sabe-se que as condições climáticas e do solo - Cerrado - propiciaram boa adaptação da cultura no Estado. Ainda segundo os autores, é possível analisar que o alto grau de competitividade da soja de MS foi possível pela evolução tecnológica que proporcionou modernização nas máquinas, equipamentos utilizados e insumos. Hipótese esta confirmada também por Neto (2010) quando afirma que entre os anos de 1976 e 2006 MS apresentava maior área plantada, comparado a MT. Com relação à produtividade, MS apresentou maior oscilação para o período, comparado a MT. No entanto, com relação à produção MS é superado por MT na safra de 1986/1987 (CONAB, 2011), influência esta que, provavelmente, advém dos incentivos públicos - políticas públicas de protecionismo - recebidos pelos produtores de MT.

Conforme Tavares (2004), embora o Brasil possua vantagens comparativas substanciais frente às demais grandes economias produtoras de soja, o escoamento do produto é prejudicado pelos altos custos de logística, devido às deficiências rodoviárias e portuárias do país, lesando desde o produtor até o consumidor final. Pode-se ressaltar a importância das políticas públicas como meio de melhoramento 
da infraestrutura, viabilizando o escoamento da produção de modo a diminuir os custos dos produtores, aumentando desta forma a competitividade. Considerando a importância de MS na produção de soja no contexto nacional e objetivando identificar a interferência das políticas públicas na competitividade, formula-se o seguinte problema de pesquisa: Quais as principais variáveis que impactam na competitividade de MS?

A análise da competitividade da soja em grãos de MS será baseada na teoria da Matriz de Análise de Política (MAP). Desenvolvida por Monke e Pearson em 1989, a matriz proporcionará a compreensão do impacto das políticas públicas nas variáveis de maior relevância na competitividade no Estado.A contribuição acadêmica do presente trabalho possibilitará a análise das principais variáveis relacionadas à competitividade de MS na produção de soja, de forma que esta informação permitirá que as autoridades públicas reconheçam as falhas deste mercado e as corrijam por meio de políticas agrícolas que regulem a variável identificada de maior peso, impulsionando assim a competitividade do Estado. O estudo está baseado na MAP, que possibilitará averiguar os efeitos causados pela interferência política, por meio de subsídios, na produção de soja. O modelo possibilita a análise de indicadores capazes de avaliar a interferência dos subsídios na competitividade, de modo que esta pesquisa possibilitará a verificação da contribuição social tanto para o produtor rural, em termos de competitividade, quanto para o governo, em termos de alocação de recursos.

Cabe destacar que diversos estudos já foram realizados para verificar a competitividade do produto no Estado, tais como: Alvim e Oliveira (2005); Coronel, Alves e Santos (2012) e Fagundes e Tomas (2011). Entretanto, cada artigo tem objetivos distintos. Este difere dos demais por discutir os efeitos da intervenção governamental sobre essa competitividade.

Desta forma, este estudo teve como objetivo geral analisar os efeitos da intervenção governamental na competitividade de produção de soja em grãos em MS, por meio dos indicadores econômicos obtidos na MAP.

\section{REFERENCIAL TEÓRICO}

\subsection{Competitividade}

A competitividade é considerada por Alvim e Oliveira (2005) como a combinação de distorções do mercado e vantagens comparativas, de modo que, para o autor, as distorções de mercado são consequência tanto de políticas econômicas como de competição imperfeita entre as firmas, sendo que termos como produtividade e lucratividade são essenciais para a análise de competitividade. Sabe-se que a competitividade pode ser afetada por políticas econômicas que causam um "peso morto" para os consumidores e produtores, ou seja, para a sociedade em geral, diminuindo dessa forma a eficiência econômica, definida por Pindyck, Rubinfeld (2010) como a maximização do excedente do consumidor e do produtor em conjunto. Logo, pode-se concluir que a política impõe um custo de eficiência à economia.

De acordo com Neto (2005), o termo eficiência agrega a competitividade de uma economia às suas particularidades fundamentais, isto é, define-se como o potencial da empresa em gerar determinados produtos de modo mais favorável em relação aos seus concorrentes. Nos termos apresentados pelo autor, a competitividade pode ser instituída ou ampliada por melhoramento tecnológico, mudanças organizacionais, busca de vantagens relacionadas ao melhor aproveitamento de economia de escala, maior habilitação e preparação técnica por parte dos trabalhadores.

Segundo Porter (1999), a competitividade pode ser classificada como "produto do esforço humano", de modo que a competitividade de um país esteja atrelada à capacidade de inovação e aprimoramento de sua força industrial. A construção da competitividade se dá pela existência de rivais, formação de barreiras à entrada, base de fornecedores nacionais e pela presença de clientes exigentes. O autor elucida que valores nacionais, culturais, institucionais, de estrutura econômica e até mesmo a própria história podem ser fatores diferenciadores no âmbito competitivo. Portanto, observa-se que dificilmente um país será competitivo em setores muito amplos de sua economia, pois como demonstrado, é necessário que o ramo seja "progressista, dinâmico e desafiador". 
Conforme Porter (1999), é possível associar divergentes conceitos à competitividade, como a possibilidade de a mesma ser um fenômeno macroeconômico induzido por políticas fiscais ou monetárias. Outros argumentam que a competitividade é oriunda da mão de obra barata e abundante. Também há os que associam competitividade à abundância de recursos naturais e, entre tantas outras visões, há aquelas que aceitam a participação do governo mediante políticas protecionistas, concentração de recursos, ou seja, como o grande financiador da competitividade. No entanto, o autor qualifica as opiniões anteriores como insatisfatórias para explicar um conceito tão abrangente, pois para o mesmo, a competitividade pode ser avaliada pelo princípio da produtividade, porquanto é por meio da elevada produtividade do capital e do trabalho, por exemplo, que um país é capaz de proporcionar qualidade de vida aos seus cidadãos. Na verdade, é necessário que os países busquem pelas vantagens comparativas de forma que seja valorizado o êxito internacional em setores que sustentem a "elevada e crescente produtividade".

Um complemento à visão porteriana é a de Arbage (2001), que acredita que para uma empresa se tornar competitiva não se deve levar em conta apenas sua estrutura de custo, mas primeiramente observar as oportunidades e ameaças do mercado, e só então elaborar estratégias organizacionais adequadas ao mercado em que a empresa está inserida, reconhecendo suas fraquezas e potencialidades internas, e então analisar a economia dos custos, pois acredita que por meio da análise da estrutura organizacional e formulação estratégica se impulsiona a competitividade.

A análise da competitividade em um ambiente caracteristicamente empresarial pode ser observada em Farina (1999), que ressalta a coordenação vertical como um elemento essencial da competitividade, de forma a viabilizar estratégias e melhor aproveitamento das oportunidades de lucro. Para a autora, a competitividade é a capacidade sustentável — realização de lucros não negativos - de sobreviver e crescer em mercados concorrentes. Uma das propostas da autora para corrigir as falhas de mercado é a interferência do governo por meio de regulamentações.

O mercado da soja é caracterizado por um grande número de produtores no qual não há diferenciação no produto, sendo o mercado de abrangência mundial, de modo que a produção individual é considerada insignificante ao analisar a produção total; disto, infere-se que os produtores não têm poder de influenciar o preço de mercado; desta forma, são tomadores de preço. Com isso, o mercado agrícola possui propriedades e similaridades ao modelo de concorrência perfeita, modelo este que, segundo Pindyck, Rubinfield (2010) obedece três princípios básicos: (1) Tomador de preços, isto é, as empresas, devido sua produção individual representar uma parcela insignificante da produção total, não têm poder de influenciar nos preços; (2) Homogeneidade de produtos, caracteriza um mercado do qual todas as empresas produzem produtos semelhantes, produtos estes considerados substitutos perfeitos entre si; (3) Livre entrada e saída, propriedade que expressa a ausência de barreiras de entrada e saída de empresas neste mercado.

Segundo Neto (2005), para realização do estudo da competitividade das atividades inseridas no setor agroindustrial de um país é preciso estimar, não apenas os custos inseridos na produção, mas incluir neste fator o peso do custo de comercialização, porquanto o êxito da competitividade não está exclusivamente relacionado com os custos de produção. De modo geral, a competitividade é consequência dos custos de produção e do conjunto de todos os demais custos incidentes, da produção ao consumidor final.

Um dos custos que incidem desde o produtor até o consumidor final são as tributações impostas pelas políticas públicas nacionais. De acordo com Coutinho e Ferraz (1993), as políticas públicas podem moldar a competitividade na economia nacional por meio de estratégias do governo com as empresas privadas, principalmente em setores com desenvolvimento tecnológico. Assim, com a criação de benefícios como condições favoráveis, tanto internas quanto externas, parcerias, fornecedores, mão de obra, infraestrutura, obtém-se um mercado competitivo eficiente.

\subsection{Políticas públicas}

Ao discutir questões relativas às falhas de mercado no setor agrícola, nota-se que apesar de afetar positiva ou negativamente a competitividade, a intervenção estatal na atividade é necessária. Segundo Carvalho (2001), as falhas encontradas no setor agrícola podem incluir o uso de bens públicos, mercados imperfeitos, 
externalidades e informação insuficiente. Isso gera riscos e incertezas e, consequentemente, erros na alocação de recursos que causam crises subsequentes, seja pelo excesso de produção ou insuficiência de oferta - tais fenômenos afetam a estabilidade econômica do setor.

Existem diversos conceitos que definem políticas públicas. De acordo com Teixeira (2002) elas consistem em regras e procedimentos para as relações entre o poder público e a sociedade, explicitadas, sistematizadas ou formuladas em documentos, normalmente com a utilização de recursos públicos. Incluem também as "não ações", as omissões do governo perante as situações apresentadas. Ainda segundo o autor, a implementação dessas políticas é uma forma de exercício de poder político e distribuição do direito de decisão.

O campo de atuação do governo por meio das políticas é vasto, e para analisar seus impactos na área do agronegócio deve-se especificar quais os objetivos e situações utilizados no emprego dessas políticas. Segundo Azevedo (2003), elas possuem duas características gerais; primeiro, a busca de um consenso sobre qual objetivo seguir ou não seguir, pois quanto maior for o consenso entre as partes envolvidas, melhor será a sua realização; segundo, são definidas normas que regulam os eventuais conflitos dos indivíduos envolvidos na construção das políticas.

Ainda segundo Azevedo (2003), as políticas públicas podem ser divididas em três tipos: políticas redistributivas, distributivas e regulatórias. O objetivo das redistributivas é redistribuir a renda na forma de recursos e financiamentos (estes, partindo dos estratos sociais de alta renda, beneficiando os de baixa renda). Um exemplo de execução desse tipo de política é a cobrança de uma taxa de IPTU maior às classes mais abastadas, acompanhada de uma redução da taxa aos mais pobres, ainda assim mantendo o nível de arrecadação. As políticas distributivas consistem em utilizar o orçamento geral arrecadado pela sociedade para beneficiar diferentes camadas sociais que, eventualmente, demandam um maior apoio financeiro, como no caso da necessidade de pavimentação e iluminação de ruas ou a aquisição de equipamentos específicos para portadores de deficiência física. Esse tipo de política é a mais aplicada no país, pois a oposição de outros estratos sociais é mínima, apesar de sua efetivação não ser assegurada por nenhuma lei.
Por fim, o autor descreve as políticas regulatórias, que visam regular um determinado setor criando normas para o funcionamento de serviços e implementação de equipamentos urbanos. Estas se referem à legislação e normatizam a aplicação dos outros tipos de políticas anteriormente mencionados, ao mesmo tempo que não beneficiam classes sociais propriamente ditas, atingindo a sociedade de maneira transversal e subsidiando diferentes grupos e setores. Nessa categoria podem-se incluir as políticas econômicas (fiscal, monetária e cambial), pois estas possuem caráter regulatório em relação ao funcionamento da economia.

De acordo com Rezende (2009), a política fiscal busca três grandes objetivos: estabilização da economia mediante a regulação dos preços e do estímulo da produção e do emprego; redistribuição da renda, com tributação às camadas mais ricas; e alocação e fornecimento de bens públicos para a comunidade. As políticas fiscais podem ser expansionistas ou contracionistas, e utilizam os impostos e gastos governamentais como instrumentos de implementação pelo governo, afetando positiva ou negativamente a renda nacional.

A política monetária é usada para controlar o dinheiro à disposição dos agentes econômicos, tratando-se de um mecanismo utilizado pelo governo que eleva ou diminui a oferta de moeda, influenciando assim o aumento ou a diminuição do consumo, produção e preços. Por fim, a política cambial consiste no controle do valor das moedas estrangeiras negociadas no país, sendo representadas pela taxa de câmbio - esta é determinada de acordo com o regime cambial adotada pelo governo, e afeta as importações e exportações. A escolha de qualquer dessas políticas gera impactos recessivos ou expansivos no sistema econômico como um todo.

As políticas econômicas geram impacto sobre a produção e comércio de bens finais e matéria-prima. No mercado da soja em grãos, a implementação de políticas fiscais acaba por determinar o nível de produção e de exportação; no começo da década de 1990, a exportação da soja em grãos representava apenas 12,4\% da demanda total de soja no país. Após a promulgação da Lei Kandir, que isenta do tributo ICMS os produtos básicos destinados a este fim, o ritmo das exportações da oleaginosa cresceu de tal forma que estas passaram a responder por $38,2 \%$ da demanda total do produto 
no Brasil no triênio 2003/2005 (MAPA/SPA). Isso mostra que, segundo Lucena (2001), a agricultura brasileira depende muito das políticas do governo, estando aquém do seu potencial com políticas desfavoráveis ou desperdiçando recursos com subsídios excessivos.

No setor produtivo da soja, as políticas econômicas são fatores cruciais na determinação do preço e da competitividade do grão, por meio de atuação não só sobre a soja propriamente dita, mas também sobre os diversos insumos utilizados na produção. De acordo com Santana (1987), a intervenção sobre esse mercado é ampla: políticas de contingenciamento sobre fertilizantes podem ser adotadas, reduzindo a importação dos produtos químicos e aumentando seu preço no território nacional, e, consequentemente, elevando o preço da soja — por outro lado, programas de crédito rural estimulam a produção a taxas de juros subsidiadas, elevando a demanda do produto. Em suma, é notória a capacidade de intervenção do governo sobre a soja mediante políticas econômicas.

\section{METODOLOGIA}

O método aplicado na obtenção e análise dos dados é quantitativo, pois se baseia em informações quantificadas para a geração dos resultados, utilizando técnicas exatas. Tal aplicação tem o objetivo de mostrar relações entre as variáveis previamente estabelecidas, assim como suas influências sobre outras, investigando a causalidade entre fenômenos e classificando suas semelhanças e diferenças para atingir um resultado consistente.

No trabalho, utilizam-se as teorias da competitividade, custos privados e sociais, fatores de produção e políticas governamentais, com o objetivo de analisar a concorrência dos produtores de soja. A MAP foi empregada para observar os impactos das divergências causadas por políticas "distorcidas" e falhas de mercado na produção de soja.
Este método constitui um instrumento contábil que estuda as rentabilidades privada e social por meio do estabelecimento de dois sistemas contábeis distintos constituídos pelos preços de mercado (privados) e preços sociais, possibilitando a ponderação do êxito das medidas dos formuladores de políticas agrícolas. A matriz objetiva desenvolver estratégias de adaptação da produção, fundamentadas em projetos de alocação de recursos na infraestrutura produtiva e na substituição da tecnologia sucateada pela de ponta.

\section{Segundo Tôsto et al. (2005)}

o método da MAP permite medir o impacto da intervenção do governo na lucratividade privada dos sistemas agrícolas e na eficiência econômica no uso dos recursos. Essas abordagens focalizam os efeitos das medidas de política, determinando a diferença entre a lucratividade privada e o benefício social, a qual é definida pelo efeito das divergências.

Na MAP (Quadro 1), o lucro é expresso a partir da diferença entre receitas e custos, sendo o custo composto por insumos transacionáveis e fatores domésticos, de forma que o cálculo dos lucros obtidos exibe a competitividade do sistema produtivo. Por meio da análise do lucro são três os resultados possíveis: lucros menores que zero, ou seja, lucro privado negativo, significando que os custos de produção excedem as receitas obtidas (desta forma os produtores tendem a deixar a atividade, caso políticas públicas não venham exercer influência positiva sobre os lucros, seja gerando receita ou subsidiando os custos); lucros iguais a zero, ou seja, embora os lucros não sejam extraordinários, a receita obtida é capaz de cobrir todo o custo de produção; e, por fim, lucro acima de zero, que significa lucros extraordinários, podendo inferir que poderá ocorrer expansão na produção deste produto.

Quadro 1: Modelo da Matriz de Análise de Política.

\begin{tabular}{|l|c|c|c|c|}
\hline \multirow{2}{*}{} & \multirow{2}{*}{ Receita } & \multicolumn{2}{|c|}{ Custo } & Lucro \\
\cline { 3 - 5 } & & $\begin{array}{c}\text { Insumos } \\
\text { (transacionável) }\end{array}$ & $\begin{array}{c}\text { Fatores domésticos } \\
\text { (não transacionável) }\end{array}$ & $\mathrm{C}$ \\
\hline Preços privados & $\mathrm{A}$ & $\mathrm{B}$ & $\mathrm{G}$ & $\mathrm{D}$ \\
\hline Preços sociais & $\mathrm{E}$ & $\mathrm{F}$ & $\mathrm{K}$ & $\mathrm{H}$ \\
\hline Divergências & $\mathrm{I}$ & $\mathrm{J}$ & $\mathrm{L}$ \\
\hline
\end{tabular}


Para a elaboração da MAP reúnem-se dados referentes ao preço de mercado do produto, preço dos insumos e dos fatores domésticos utilizados na produção. Para o cálculo da receita foi utilizada a média de preços e a produtividade relativa ao ano de 2011; os custos são divididos entre insumos e fatores domésticos, sendo que no primeiro utilizou-se o custo dos fertilizantes, sementes, defensivos agrícolas e outros produtos químicos; já os fatores domésticos englobam os custos operacionais, administrativos e pós-colheita (dados numéricos foram extraídos da Revista Agrianual, 2011). Como preços privados e sociais foi utilizada a média de preços de MS e de MT relativos ao ano de 2011, respectivamente. Ressalta-se que todas as unidades de medida utilizadas são de reais por hectare.

As divergências entre preços de MS e MT podem estar associadas a três fatores: impostos e subsídios, políticas para aumentar a eficiência e imperfeições de mercado. Alguma literatura aponta que a eliminação das políticas que causam distorções e geram divergências pode proporcionar eficiência econômica e de produtividade, de forma que sejam atingidos maiores níveis de renda e remuneração dos recursos mais escassos.

Lucro privado (LP): $D=A-B-C$

Razão de custo privado: $P C R=C /(A-B)$

Lucro social (LS): H=E-F-G

Razão de custo dos recursos domésticos: $D C R=G /(E-F)$

Transferência líquida de políticas (TLP): L=D-H ou L=I-J-K

Coeficiente de proteção nominal: $C P N=A / E$

Coeficiente de proteção efetiva: $C P E=(A-B) /(E-F)$

Coeficiente de lucratividade: $C L=(A-B-C) /(E-F-G)$ ou $C L=D / H$

Razão de subsídio ao produtor: $\mathrm{RSP}=\mathrm{L} / \mathrm{E}$ ou $\mathrm{RSP}=(\mathrm{D}-\mathrm{H}) / \mathrm{E}$

Os indicadores seguintes serão definidos segundo Oliveira, 2001:

\subsection{Lucro privado}

Indicador de competitividade para uma cadeia, e permite a comparação entre cadeias e sistemas de produção do mesmo produto. Este indicador expõe resultados financeiros importantes para avaliação da lucratividade de toda a cadeia, com base na unidade do produto final processado. Indicador maior que zero mostra que o sistema é competitivo.

\subsection{Razão de custo privado}

Indicador de competitividade para uma cadeia individual e para comparação entre cadeias diferentes. Quando menor essa razão, maior será a competitividade da cadeia. Se esse indicador for igual à unidade, o valor adicionado é igual à remuneração dos fatores domésticos, ou seja, o lucro é zero. Valor inferior à unidade indica que os fatores de produção domésticos estão recebendo menos que seu retorno normal. Minimizar o PCR significa maximizar o lucro privado na cadeia.

\subsection{Lucro social}

Mede a eficiência da cadeia agroindustrial ou sua vantagem comparativa, e ordena as várias cadeias ou os sistemas de acordo com o grau de eficiência, desde que tratem de um mesmo produto. Quando este indicador for positivo, o sistema em análise gasta recursos escassos para a produção a preços sociais, que ficam além dos custos privados.

\subsection{Razão de custo dos recursos domésticos}

Estima cada cadeia e compara cadeias ou sistemas que produzem produtos dessemelhantes, a exemplo do PCR para lucros privados este indicador é medida de vantagem comparativa, para DRC o valor desse coeficiente indica se o lucro é positivo ou não.

\subsection{Transferência líquida de políticas}

É a soma dos efeitos de todas as políticas consideradas, ou seja, efeitos sobre o preço do produto, sobre o custo dos insumos comercializáveis e sobre o custo dos fatores. Direciona para a necessidade de reformas mais completas nas políticas, para eliminar as transferências 
de renda das cadeias para os consumidores ou outros setores da economia, e para a utilização mais eficiente dos recursos escassos por ela usados.

\subsection{Coeficiente de proteção nominal}

É a divisão (comparação) do preço privado pelo preço equivalente internacional. É uma medida da proteção diretamente concedida à cadeia, e permite a comparação das transferências entre sistemas que produzem produtos distintos. Baseia-se na relação entre o valor privado e o valor social da cadeia. Este indicador capta o efeito de todas as distorções ou as intervenções diretas sobre os mercados do produto da cadeia.

\subsection{Coeficiente de proteção efetiva}

É a razão entre o valor adicionado a preços privados e o valor adicionado a preços sociais. Considera os efeitos de políticas distorcidas sobre os produtos e os insumos comercializáveis. Avalia o quanto as políticas que afetam os mercados de produtos fazem o valor adicionado diferir do valor que ocorreria na ausência de políticas para as cadeias.

\subsection{Coeficiente de lucratividade}

É a razão entre o lucro privado e o lucro social. Mede o efeito de todas as políticas e serve como proxy da transferência liquida de políticas. Fornece uma ideia de distância entre o lucro privado e o lucro que se conseguiria na ausência de políticas causadoras de distorções.

\subsection{Razão de subsídio ao produtor}

É a transparência liquida de política como proporção da receita social total. Permite comparações sobre a extensão em que as políticas subsidiam os sistemas, e pode ser desagregado para apresentar os efeitos de políticas de produtos, insumos e fatores. Quanto menor o valor absoluto deste indicador, menores são os subsídios existentes nas cadeias.

\section{RESULTADOS E DISCUSSÃO}

Em primeiro lugar, é necessário discutir as propriedades nutricionais do grão de soja, composto basicamente por proteínas, gorduras, carboidratos, umidade e minerais. Com isso, é possível analisar as relações da cadeia produtiva da soja, que abrange desde a produção interna destinada a exportação até a conversão do grão dirigido à indústria esmagadora, onde a soja é processada e transformada em farelo ou óleo, sendo que seu consumo se dá tanto no mercado interno quanto no mercado externo por meio das exportações (SILVA, LIMA, BATISTA, 2011).

Segundo o trabalho de Buainaim, Vieira, Vieira Junior (2006), pode-se analisar da representação esquemática da soja no Brasil (Quadro 2) os seguintes aspectos: a relação de consumo (T18) refere-se ao consumidor de óleos e outros produtos derivados da soja, sendo que este consumidor pode estar representado no mercado interno ou externo; a cadeia T15 é composta pelas indústrias de alimentos derivados da soja, como maioneses, e também indústrias de sabão e cosméticos; a cadeia T10 refere-se, prioritariamente, à indústria de óleos; as indústrias de rações (T12) são caracterizadas como consumidoras intermediárias da soja; outro segmento essencial da cadeia produtiva é a T8 que se refere às indústrias esmagadoras de soja, que proporcionam, entre outros produtos, óleo bruto, óleo refinado e o farelo de soja; entre outros aspectos e peculiaridades que a cadeia representa, mas que não serão retratados neste trabalho.

Pela Tabela 1 observam-se os custos com a produção de soja em grãos nos Estados de MT e MS, obtidos por meio da revista Agrianual 2011, elaborada pela empresa de consultoria em agronegócio Informa Economics FNP. Os dados da tabela foram expostos em reais por hectare $(R \$ / h a)$.

Com relação aos custos observa-se: (1) os custos com operações são similares para os dois Estados, de forma que a justificava paire na semelhança de intempéries enfrentada pelos solos das respectivas regiões. Sabe-se que a degradação do solo é causada por circunstâncias climáticas, condições naturais do próprio solo e cultura plantada. No caso analisado, a cultura é a mesma para os dois Estados e, embora haja condições climáticas favoráveis ao cultivo em MS, o solo da região central do Brasil encontra-se, de maneira geral, em área de Cerrado; (2) os custos com insumos, diferentemente dos demais, apresentam grande disparidade que pode ser justificada pelo alto custo dos 
Quadro 2: Representação da cadeia da soja no Brasil.

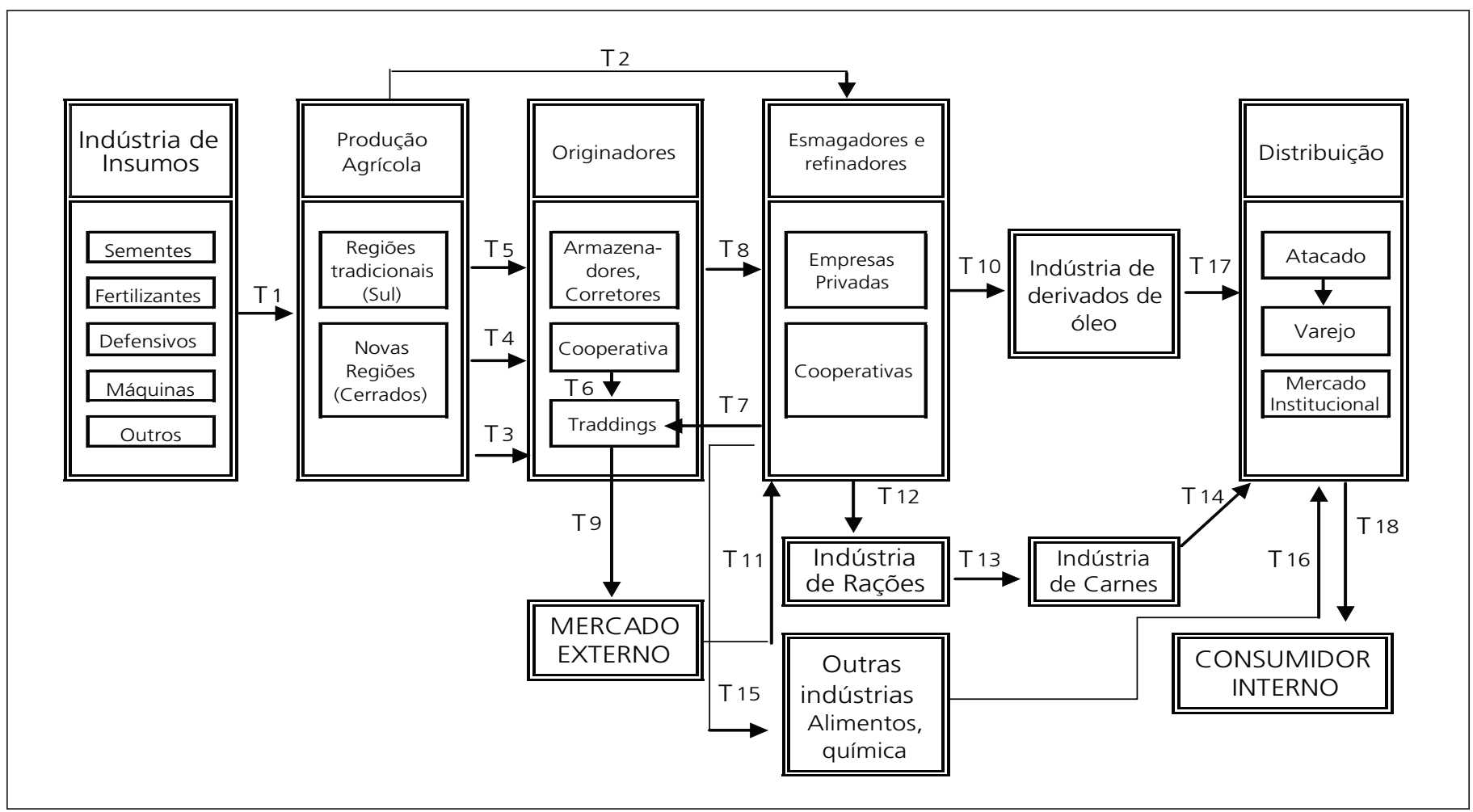

Fonte: Lazzarini e Nunes (1998).

fertilizantes/corretivos em MT. De acordo com a Aprosoja, 2012, o Brasil importa 50\% do fósforo, 75\% do nitrogênio e $90 \%$ do potássio usados como matéria-prima para os fertilizantes, os quais são amplamente utilizados pelos Estados de MS e MT. No entanto, o Estado de MT é prejudicado pela distância dos grandes portos pelos quais esses insumos chegam, o que além de encarecer seus custos revela os graves problemas com transporte, demonstrando a dificuldade de escoamento da soja devido à debilitação do processo de vazão de produtos agrícolas pelas rodovias, que se encontra em condições precárias, pela ineficiência e ausência de capacidade das ferrovias e pela desordem e demasiada burocracia dos portos; além disso, a baixa fertilidade do solo mato-grossense acaba por exigir uma maior quantidade de fertilizantes; (3) a pequena diferenciação nos custos com o pós-colheita se dá, principalmente, pelos gastos com o transporte até o armazém; especula-se que isso acontece devido à alta produtividade por hectare em MT, que exigiria maior número de veículos para a locomoção dos grãos; e, por fim, (4) os fatores fixos envolvem principalmente os custos administrativos, os quais não apresentam diferenças significativas para os dois Estados.

A seguir, apresenta-se uma comparação gráfica (Gráfico 1) agregada dos custos fixos e variáveis, em que os custos com operação, insumos e pós-colheita são considerados variáveis, enquanto os custos administrativos foram adotados como fixos.

Assim, são apresentados os resultados da MAP na Tabela 2 segundo a metodologia de Monke e Pearson (1989). Ressalta-se que os preços sociais utilizados referem-se à média de preços do ano de 2011 no Estado de MT, e os preços privados, a média de preços de MS no ano de 2011. Os valores apresentados na matriz referem-se à safra 2011/2012, em $\mathrm{R} \$ /$ ha.

Visivelmente, a MAP revela uma divergência entre as receitas dos dois Estados. O cálculo da receita foi elaborado pela multiplicação dos preços médios de 2011 pela produtividade da safra do mesmo período 
Tabela 1: Custos fixos e variáveis de Mato Grosso do Sul e Mato Grosso em R\$/ha.

\begin{tabular}{|c|c|c|}
\hline Variáveis & MS & MT \\
\hline \multicolumn{3}{|l|}{ 1. Operações } \\
\hline Conservação do solo & 8,46 & 8,46 \\
\hline Preparo do solo & 14,71 & 14,74 \\
\hline Plantio & 42,73 & 42,73 \\
\hline Tratos culturais & 68,62 & 59,15 \\
\hline Colheita & 119,92 & 119,92 \\
\hline \multicolumn{3}{|l|}{ 2. Insumos } \\
\hline Fertilizantes/Corretivos & 316,10 & 438,50 \\
\hline Sementes/mat. Plant. & 115,74 & 119,47 \\
\hline Defensivos agrícolas & 155,61 & 115,78 \\
\hline \multicolumn{3}{|l|}{ 3. Pós-colheita } \\
\hline Transporte até o armazém & 25,89 & 43,88 \\
\hline Recebimento/limpeza/secagem & 57,50 & 58,30 \\
\hline Armazenagem (1 mês) & 13,80 & 15,90 \\
\hline Taxa administrativa & 7,13 & 7,42 \\
\hline \multicolumn{3}{|l|}{ Fixo } \\
\hline Mão de obra administrativa & 28,85 & 20,44 \\
\hline Assistência técnica & 16,03 & 11,35 \\
\hline Contabilidade/Escritório & 3,21 & 2,27 \\
\hline Luz/ Telefone & 6,41 & 4,54 \\
\hline Conservação/Deprec. Benf. & 9,31 & 6,21 \\
\hline Viagem & 7,16 & 5,07 \\
\hline Impostos/Taxas & 46,55 & 51,81 \\
\hline Total & $1.063,73$ & $1.145,94$ \\
\hline
\end{tabular}

Fonte: Elaboração própria.

Gráfico 1: Custos operacionais com insumos, pós-colheita e administrativos em $\mathrm{R} \$ /$ ha.

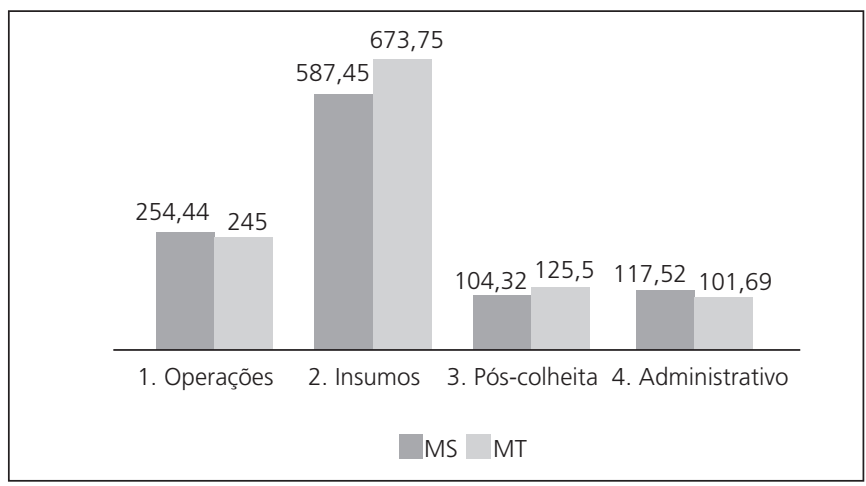

Fonte: Elaboração própria. por hectare. Com isso, a diferença das receitas se dá pela pequena disparidade de $\mathrm{R} \$ 0,05$ entre os preços por hectare de cada Estado (MS: R 0,69/ha; MT: $R \$ 0,64 /$ ha), em que MT obtém o menor preço devido à caracterização do mercado agrícola como mercado de competitividade perfeita, ou seja, por MT possuir a maior produção nacional de soja, seus preços tendem a ser menores, respeitando a lei de mercado, na qual quanto maior for a produção, menor será o preço.

Com relação à produtividade, é possível notar pelo Gráfico 2 que embora sejam diferentes - cerca de 420 kg/ha de discrepância na safra 2011/2012 — os Estados de MT e MS apresentam similaridades tecnológica e climática. As variações negativas do Estado de MS podem ser explicadas por fatores naturais como pestes e desregulamentações metereológicas.

De acordo com uma análise da Agrianual, 2011, é possível observar que os custos desagregados com a colheita são idênticos para os Estados de MT e MS. Nota-se a presença enfática da mecanização na colheita dos Estados, representada por $97 \%$ dos custos com a colheita, em contrapartida ao serviço braçal que representou apenas 1\% dos custos, nos dois Estados, na safra de 2011/2012. Sabe-se que a topografia da região Centro-Oeste favoreceu a mecanização desde o início do cultivo da soja no Brasil devido ao relevo de Cerrado ser caracterizado por áreas planas. Com isso, os dois Estados foram beneficiados com a economia de mão de obra e maior produtividade nas operações de preparo do solo, tratos culturais e colheita.

Pelos resultados dos indicadores da MAP (Tabela 3), a razão de custo privado de 0,36 reforça a competitividade da soja em MS, devido ao fato de que quanto mais próximo de zero o indicador, maior o lucro. As razões de custo sociais evidenciam, pelo mesmo argumento da razão de custos privados, a competitividade em MT. No entanto, uma análise mais apurada permite

Tabela 2: Matriz de Análise de Política em $\mathrm{R} \$ /$ ha.

\begin{tabular}{l|c|c|c|c}
\hline & \multirow{2}{*}{ Receita } & \multicolumn{2}{|c}{ Custos de produção } & \multirow{2}{*}{ Lucro } \\
\cline { 3 - 5 } & & Insumos & Fatores domésticos & 837,78 \\
\hline Preços de MS & $1.896,12$ & 587,45 & 475,89 & 884,49 \\
\hline Preços de MT & $2.030,43$ & 673,75 & 472,19 & $-51,6$ \\
\hline Divergências & $-134,31$ & $-86,3$ & 3,59 & \\
\hline
\end{tabular}

Fonte: Elaboração própria. 
Gráfico 2: Produtividade no cultivo da soja em grãos de MS e MT em kg/ha.

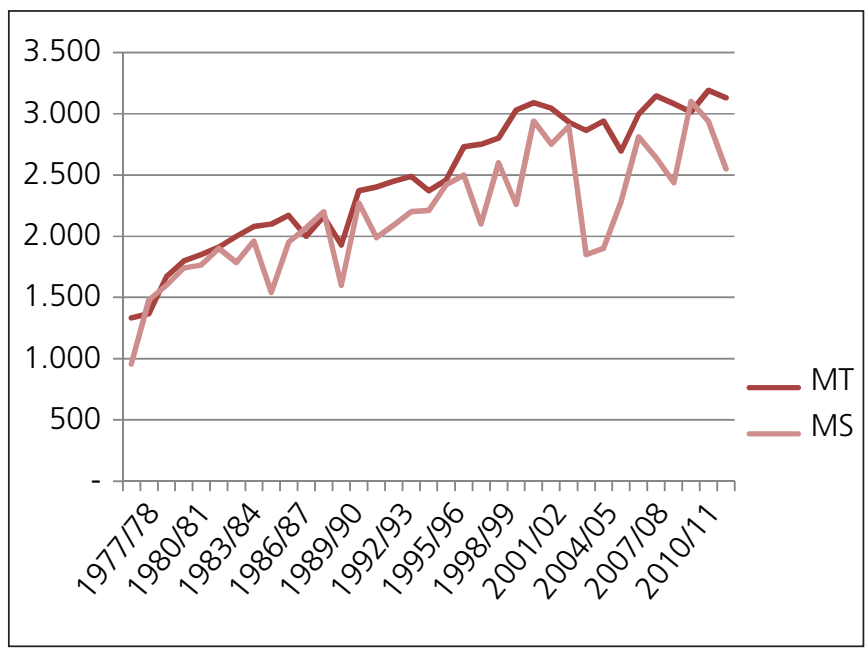

Fonte: Elaboração própria.

Tabela 3: Resultado da Matriz de Analise de Política - Indicadores.

\begin{tabular}{l|c}
\hline Indicador & \\
\hline Razão de custo privado & 0,36 \\
\hline Razão de custo dos recursos domésticos & 0,36 \\
\hline Coeficiente de proteção nominal & 0,93 \\
\hline Coeficiente de proteção efetiva & 0,96 \\
\hline Coeficiente de lucratividade & 0,94 \\
\hline Razão de subsídio ao produtor & $-0,02$ \\
\hline
\end{tabular}

Fonte: Elaboração própria.

comprovar que MT é mais competitivo que MS, visto que 0,35 é menor que 0,36.

O coeficiente de proteção nominal de 0,93 faz referência à diferença de receita existente entre os Estados. Dado que o preço, como já dito, é diferente por relações do próprio mercado agrícola, infere-se que a perda de competitividade por MS possivelmente relaciona-se com a diferença de produtividade entre os Estados (MS: 2.760 $\mathrm{kg} / \mathrm{ha}$; MT: $3.180 \mathrm{~kg} / \mathrm{ha}$ ), de forma que a peça-chave de MT é a presença do governo na alocação eficiente dos subsídios, principalmente na aquisição tecnológica.

O coeficiente de proteção efetiva de 0,96 reforça as diferenças de produtividade e custos com insumos entre MS e MT, ou seja, destacando novamente a maior eficiência do governo mato-grossense em subsidiar a tecnologia. O indicador é maior que o coeficiente de proteção nominal, pois agrega o valor dos insumos, nitidamente menor em MS.
O coeficiente de lucratividade representa a razão dos lucros de MS por MT, de forma que se pode medir a diferença de transferência líquida de políticas. Por meio desse indicador é possível analisar a diferença de lucratividade que seria obtida na presença de políticas públicas mais eficientes para a produção de soja em grãos em MS, ao ser examinado em conjunto com MT.

Por fim, indicador de razão de subsídios ao produtor de -0,03 indica que a cadeia da soja foi taxada, ou seja, existiu desproteção, provocando redução de 3\% na rentabilidade. Quanto menor for esse coeficiente, menores serão os subsídios na cadeia. Como exemplo, é possível notar incentivos com base no valor do ICMS debitado nas Notas Fiscais de saída dos produtos: óleo de soja degomado $(41,67 \%)$, farelo de soja (50\%), óleo de soja refinado (90\%). Dessa forma, analisa-se que a presença de políticas públicas atrai empresas de grande porte voltadas para o processamento da soja, o que estimula a grande concentração de produtores e, com eles, a alta produção da soja em Mato Grosso.

De acordo com dados oficiais, o governo do Estado de MT possui três principais programas de incentivo aos produtores: FCO - Fundo Constitucional de Financiamento do Centro-Oeste, voltado aos setores econômicos industrial, agroindustrial, agropecuário, mineral, turístico, comercial e de serviços; PRODEIC Programa de Desenvolvimento Industrial e Comercial de Mato Grosso, com o objetivo de contribuir para a expansão, modernização e diversificação das atividades econômicas, estimulando a realização de investimentos, a inovação tecnológica das estruturas produtivas e o aumento da competitividade estadual; e FUNDEIC - Fundo de Desenvolvimento Industrial e Comercial, que tem por objetivo propiciar recursos para financiamento de micro e pequenas empresas, estimular a produtividade das empresas já constituídas ou novas no Estado e estimular a implantação, modernização ou relocalização da atividade empresarial nos setores da indústria, comércio e turismo.

Observa-se que o Estado de MS também desempenha políticas públicas de incentivo, tais como: o apoio institucional para financiamentos de médio e longo prazo, por meio do FCO - Fundo Constitucional do Centro-Oeste, BNDES - Banco Nacional de Desenvolvimento Econômico e Social, BID - Banco 
Interamericano de Desenvolvimento, a concessão de áreas com infraestrutura básica, incentivos fiscais estaduais (redução e deferimento de impostos estaduais e municipais em diversas áreas industriais) e capacitação e treinamento de mão de obra. De acordo com informações oficiais, o governo de MS também atua na garantia do fornecimento de energia, recuperação de rodovias, pavimentação de trechos estratégicos à logística de escoamento, entre outros.

Com isso, analisa-se que embora o Estado de MS apresente ser um potencial produtor de soja em grãos e esteja entre os Estados mais produtivos do país, é necessário que os incentivos públicos sejam mais eficazes de forma a alocar melhor os recursos financeiros do Estado a fim de impulsionar a competitividade do produto, trazendo novos produtores, novas indústrias processadoras de grãos, gerando emprego, financiando tecnologia, entre outros ativos voltados para o desenvolvimento da economia regional.

\subsection{Análise de sensibilidade}

A análise de sensibilidade permite verificar as consequências que uma variação nos preços sociais promove sobre os indicadores da MAP. Dessa forma, um aumento de $10 \%$ foi aplicado sobre os custos de MT, mantendo os demais parâmetros constantes, possibilitando a compreensão dos efeitos na competitividade da soja em MS.

Os impactos foram analisados sobre os seguintes indicadores: Lucro Social, Razão de Custos dos Recursos Domésticos, Coeficiente de Proteção Efetiva, Coeficiente de lucratividade, Razão de Subsídio ao Produtor. O uso destes indicadores é justificado por apresentar o preço social no seu cálculo.

A análise de sensibilidade é justificada, além da averiguação na modificação ou não da competitividade entre os Estados de MT e MS, pela comparação dos novos dados obtidos com os resultados anteriores. As mudanças nos custos pode corrigir a inconsistência dos dados causada pela omissão de informações por parte dos órgãos competentes, considerando que as incertezas ou erros podem persistir na metodologia utilizada.
De acordo com a Tabela 4 pode-se observar, por meio dos indicadores, que a variação de $10 \%$ sobre os custos de MT proporcionou aumento na competitividade para o Estado de MS. O aumento dos custos sociais sem modificação na receita provoca uma queda nos lucros sociais, já o aumento no coeficiente de proteção efetiva demonstra que o aumento dos custos em MT pode ser causado pela redução da proteção estadual sobre a cadeia. O aumento no coeficiente de lucratividade demonstra que a transferência líquida de políticas em MT diminuiu e, portanto, a lucratividade do Estado também. O resultado deste indicador reforça a hipótese de que a elevação dos custos foi proporcionada por menor proteção na cadeia.

Por fim, analisa-se que a mudança na razão de subsídio ao produtor reflete a sensibilidade da rentabilidade em MS dado um aumento de custos em MT, ou seja, as políticas fiscais de MT menos protecionistas impactam positivamente sobre a rentabilidade em MS, afinal, a cadeia antes taxava em $2,5 \%$, agora passou a apresentar rentabilidade positiva de $3 \%$. Dessa forma, conclui-se que tanto o efeito da diminuição de proteção fiscal de MT quanto um aumento de subsídios da cadeia de soja em MS, proporcionam o aumento da rentabilidade em MS, sendo o primeiro fator observado pela própria variação na razão de subsídios ao produtor, o que, consequentemente, gera maior competitividade ao setor em MS.

\section{CONCLUSÃO}

O presente estudo possibilitou a verificação da importância da produção de soja no Estado de MS, constatando a grande expansão desta cultura. Estimativas mostram que a produção da safra de 2012/2013 deve ser 34,9\% maior que a safra anterior, sendo este fato consequência da ampliação da área plantada no Estado, passando de 1.815 para 2.067 milhões de hectares, e do aumento da produtividade média do setor, chegando a 3 ton/ha. Este crescimento notável na produção tem impactos positivos na economia por meio da geração de renda, atração de indústrias processadoras de grãos trazendo novas técnicas de produção, tecnologia de ponta, e criando novos empregos (tendo em vista que o crescimento do mercado da soja expandiu o número de empregos formais) ${ }^{1}$. 
Tabela 4: Análise de sensibilidade.

\begin{tabular}{l|c|c}
\hline Indicadores & Variação de $\mathbf{1 0} \%$ sobre os Custos Sociais & Indicadores originais \\
\hline 1 - Lucro Social & 769,90 & 884,49 \\
\hline 2 - Razão de Custos dos Recursos Domésticos & 0,40 & 0,36 \\
\hline 3 - Coeficiente de Proteção Efetiva & 1,01 & 0,96 \\
\hline $4-$ Coeficiente de Lucratividade & 1,08 & 0,94 \\
\hline 5 - Razão de Subsidio ao Produtor & 0,03 & $-0,025$ \\
\hline
\end{tabular}

Assim, pode-se concluir mediante a análise dos indicadores proporcionados pela MAP que o Estado de MS é competitivo devido à sua alta produtividade, que impacta em uma receita elevada, possibilitando desta forma que os produtores sejam capazes de cobrir seus custos de produção e, portanto, obter um lucro maior que zero.

Fundamentando-se no indicador de razão de subsídios ao produtor é possível notar que MS é taxado. Com isso, percebe-se que os produtores não são incentivados por parte do governo a cultivar a soja no Estado, como é possível observar na perda de rentabilidade em $2 \%$ sofrida por MS. Assim, é cabível propor políticas públicas que viabilizem as condições econômicas de maneira favorável aos produtores, ou seja, propor incentivos fiscais, subsídios à tecnologia, isenção de taxas e, por fim, qualificação da mão de obra. E esses resultados podem ser observados pela análise de sensibilidade.

Embora a MAP possibilite constatar a fragilidade nas políticas públicas em MS, nota-se que a mesma proporciona resultados estáticos, restringindo a análise do problema apenas a um ano ou a uma safra. No entanto, é possível aprimorar a matriz à medida que se empreguem dados mais dinâmicos como, por exemplo, dados que acompanhem a sazonalidade. Dessa forma, a MAP mostra-se confiável para tomada de decisões privadas e de cunho político.

Como sugestão para trabalhos futuros, cabe destacar como possibilidade a ampliação do estudo da MAP para o cenário internacional, comparando MS com regiões de maior potencial tecnológico, podendo avaliar a sua competitividade neste sentido.

\section{REFERÊNCIAS}

AGRIANUAL. Anuário da Agricultura Brasileira. São Paulo: IFNP, 2012.

ALVIM, M.I.S; OLIVEIRA, Jr. L.B. Análise da Competitividade da produção de soja no sistema de plantio direto no Estado de Mato Grosso do Sul. Revista de Economia e Sociologia Rural, v. 43, n. 03, p.506-527, julho/set 2005. ANEC. Evolução das exportações. Disponível em: http://www.anec. com.br/links.html. Acesso em: 23 de novembro de 2012.

APROSOJAMMS. (s.d.). Sobre a soja. Disponível em: <http:// www.aprosojams.org.br/soja>. Acesso em: 21 de novembro de 2012.
APROSOJA/MT. (s.d.). Entrega de fertilizantes e sementes estão atrasadas em Mato Grosso. Disponível em: <http:// www.aprosoja.com.br/comunicacao/noticias/Paginas/ Entrega-de-fertilizantes-e-sementes-est\%C3\%A1atrasada-em-Mato-Grosso.aspx>. Acesso em: 02 de fevereiro de 2013.

ARBAGE, A.P. A competitividade no agronegócio: uma contribuição à luz da economia dos custos de transação e da noção de coordenação. In: ENCONTRO INTERNACIONAL DE ECONOMIA E GESTÃO DE NEGÓCIOS/ NETWORKS AGROALIMENTARES, 3. Anais. Ribeirão Preto: PENSA/FUNDACE/USP, 2001. 


\section{REFERÉNCIAS}

AZEVEDO, S. Políticas públicas: discutindo modelos e alguns problemas de implementação. [S.I.]: FASE, 2003.

BUAINAIM, A. M.; VIEIRA, A. C. P.; VIEIRA JUNIOR, P. A. Análise da governança da cadeia da soja. Instituto de Economia. Campinas, [s.n.], 2006.

BRASIL. Ministério da Agricultura. (s.d.). Culturas: soja. Disponível em: <http://www.agricultura.gov.br/vegetal/ culturas/soja>. Acesso em: 21 de novembro de 2012.

CARVALHO, M. A. Políticas públicas e competitividade da agricultura. Revista de Economia Política. v. 21, $\mathrm{n}^{\circ} 1$ (81), p.117-140, jan-mar 2001.

CONAB. Séries históricas relativas às safras 1976/77 a 2009/2010 de área plantada, produtividade e produção. Disponível em: <http://www.conab.gov.br/conteudos. php?a=1252\&t=\&Pagina_objcmsconteudos=3\#A_ objcmsconteudos>. Acesso em: 02 de fevereiro de 2013.

CORONEL, D. A.; ALVES, F. D.; SANTOS, N. P. A competitividade da produção de soja no Mato Grosso do Sul e na região de Ponta Porã: uma abordagem através das vantagens comparativas. Disponível em: <http://www.sober.org.br/ palestra/6/396.pdf>. Acesso em: 30 de novembro de 2012.

COUTINHO, L. G.; FERRAZ, J. C. Estudo da competitividade da indústria brasileira. Campinas: Papirus, 1993. Disponível em: <http://www.econeit.org/wp-content/uploads/2012/09/ Relat\%C3\%B3rio-final-vol1.pdf>. Acesso em: 23 de novembro de 2012.

EMBRAPA. Soja em números (safra 2010/2011). Disponível em: $<$ http://www.cnpso.embrapa.br/index.php?cod_pai=2\&op_ page=294> . Acesso em: 21 de novembro de 2012.

FAGUNDES, M. B. B.; TOMAS, R. Competitividade na produção da soja em grão entre Brasil e EUA: Uma análise utilizando a Matriz de Análise de Política (MAP). Revista FAAP. São Paulo, v. 10, n. 19, p. 45-60, julho de 2011.

FARINA, E. M. M. Q. Competitividade e coordenação de sistemas agroindustriais: um ensaio conceitual. Gestão \& Produção. São Carlos, v. 6, n. 3, p. 147-161, dez. 1999.
FUNDAÇÃO GETÚLIO VARGAS. Especial soja: preço de equilíbrio da soja. Revista Agroanalysis. São Paulo: [s.n.], 2008. Disponível em: <http://www.agroanalysis.com.br/ especiais_detalhe.php?idEspecial=24>. Acesso em: 02 de fevereiro de 2013.

IBGE. Banco de dados agregados. Disponível em: $<$ http://www.sidra.ibge.gov.br/bda/prevsaf/default. asp? $\mathrm{t}=4 \& z=\mathrm{t} \& \mathrm{o}=26 \& \mathrm{u} 1=35 \& \mathrm{u} 2=38 \& u 3=1 \& u 4=35 \mathrm{>}$. Acesso em: 21 de novembro de 2012.

LAZZARINI, S. G.; NUNES, R. Competividade do sistema agroindustrial da soja. v. 5. São Paulo: PENSA/USP, 2000.

LUCENA, R. B.; SOUZA, N. J.; Políticas agrícolas e desempenho da agricultura brasileira, 1950/2000. Disponível em: <http://www.nalijsouza.web.br.com/ pol_agr_br.pdf>. Acesso em: 25 de novembro de 2012.

MATO GROSSO. Governo do Estado. Programas de incentivo. Disponível em: <http://www.mt.gov.br/index2. php?sid=98> . Acesso em: 03 de fevereiro de 2013.

MATO GROSSO. Informação nº 018/2006-GCPJ/CGNR de 30 de março de 2006. Gerência de Controle de Processos Judiciais da Coordenadoria Geral de Normas da Receita Pública. Cuiabá, 2006. Disponível em: <http://app1. sefaz.mt.gov.br/sistema/legislacao/respostaconsulta. nsf/2e87a7055d44e0850425693400495d33/8b7dbceaa b5027990425719c004daec3?OpenDocument>. Acesso em: 03 de fevereiro de 2013.

MONKE, A. E.; PEARSON, S. R. The policy analysis matrix for agricultural development. New York: Cornell University Press, 1989.

NETO, J. F. Competitividade da produção de cana-deaçúcar no Brasil. Tese de Mestrado Universidade Federal de Viçosa, (MG), Brasil, 2005.

NETO, S. P. Perspectivas para o produtor de soja na safra 2011-2012. Disponível em: <http://www.agrolink.com. br/sementes/artigo/perspectivas-para-o-produtor-de-sojana-safra-2011-2012_142884.html>. Acesso em: 23 de novembro de 2012. 


\section{REFERÊNCIAS}

OLIVEIRA, A. J. (Org.). Cadeias produtivas no Brasil: análise da competitividade. Brasília, DF: Embrapa-SAE, 2001.

PINAZZA, L. A. (Coord.). Cadeia produtiva da soja. Série Agronegócios, vol. 2. Brasília: MAPA/SPA, 2007. Disponível em: <http://www.catagronegocio.com.br/upl oads/1/1/7/3/11739052/17135387-cadeia-da-soja.pdf>. Acesso em: 25 de novembro de 2012.

PORTER, M. E. A vantagem competitiva das nações. Rio de Janeiro: Campus, 1993.

REZENDE, R. P. Uma análise das políticas macroeconômicas do governo FHC. Florianópolis: [s.n.], 2009. Disponível em: http://tcc.bu.ufsc.br/Economia291727. Acesso em: 25 de novembro de 2012.

SANTANA, C. A. M. Efeitos das políticas econômicas brasileiras sobre o setor doméstico da soja em grão. Pesquisa e Planejamento Econômico. Rio de Janeiro: [s.n.], 1987. p. 633-678.
SILVA, A. C.; LIMA, E. P. C.; BATISTA, H. R. A importância da soja para o agronegócio brasileiro: uma análise sob o enfoque da produção, emprego e exportação. In: V ENCONTRO DE ECONOMIA CATARINENSE, 2011, Florianópolis, SC. Anais. Florianópolis: UNESC, 2011.

TAVARES, C. E. C. Fatores críticos à competitividade da soja no Paraná e no Mato Grosso. Brasília: julho, 2004. Disponível em: <http://www.conab.gov.br/OlalaCMS/ uploads/arquivos/74f269479f1f6d9ee40fb9a161eb1237. pdf>. Acesso em: 25 de novembro de 2012.

TEIXEIRA, E. C. O papel das políticas públicas no desenvolvimento local e na transformação da realidade. Políticas Públicas O Papel das Políticas Públicas. BA: AATR, 2002.

TÔSTO, S. G.; ROSADO, P. L.; GOMES M. F. M.; DO CARMO, C. A. F. S.; ASSIS, D. S. Efeito das políticas públicas sobre a produção de borracha natural em São Paulo e Mato Grosso. Rio de Janeiro: Embrapa Solos, 2005. 